\title{
Um Modelo de Firma Pós-Keynesiana
}

\author{
A model for the post-Keynesian firm
}

\author{
Gabriela Lima Aidar* \\ Fábio Henrique Bittes Terra ${ }^{\dagger}$
}

\begin{abstract}
Resumo
O objetivo deste artigo é conceber teoricamente um modelo da firma na perspectiva pós-keynesiana. $\bigcirc$ que se percebe na literatura pós-keynesiana é que há muitos elementos, porém esparsos, que configuram debates sobre a firma; logo, não há uma forma consolidada de firma, que reúna em um modelo teórico sintético estes elementos que se dispersam na literatura. Porém, se não há um retrato da firma pós-keynesiana, o que poderia servir de espelho para sua constituição? Para tanto, este artigo recorre ao que é uma firma já consolidada na teoria econômica e não incongruente com a teoria pós-keynesiana, a firma da Visão Baseada em Recursos. A partir de um conceito de firma já formado, esta teoria oferece orientação para os elementos a serem notadas para ser formar esta firma pós-keynesiana.
\end{abstract}

Palavras-chave: Teoria da Firma; Visão Baseada em Recursos; Teoria pósKeynesiana.

\begin{abstract}
This paper aims at theoretically modelling the Post Keynesian firm. What we notice in the Post Keynesian literature is that there are several elements concerning the firm theory, however they are sparse; thereby, there is not a consolidated and summarized form of firm, in which all these relevant elements are combined to synthesize the Post Keynesian firm. But, if the Post Keynesian theory has not got a portrait of the its firm, what could mirror its constitution? To do so, this paper recalls to a firm that is already consolidated in the economic theory and that is not divergent to the Post Keynesians, the one furnished by the Resource Based View. Departing from an already available firm theory, the Resource Based View approach of the firm guides what must be looked at in order to design the synthesis of the Post Keynesian firm.
\end{abstract}

Keywords: Theory of the Firm; Resource Based View; Post-Keynesian Theory. JEL Classification: E12; D00; D21.

Doutoranda do Programa de Pós-Graduação em Economia do Instituto de Economia da Universidade Federal de Uberlândia. O auxílio financeiro do Estado brasileiro, via CAPES é reconhecido com gratidão. E-mail: gabrielaaidarl@gmail.com

+ Professor da UFABC e do PPGE-UFU. Pesquisador do CNPq. O auxílio financeiro do Estado brasileiro, via financiamento do CNPq, é reconhecido com gratidão. E-mail: fabio.terra@ufabc.edu.br 


\section{Introdução}

A firma é discutida sob diversos aspectos na teoria econômica, e o mesmo pode ser dito desta discussão na teoria pós-keynesiana. Mas, resta ainda nesta literatura uma lacuna: o que seria, da união desses diversos aspectos, a firma póskeynesiana? Neste âmbito, ainda são dispersos os trabalhos, quando comparados ao grau de avanço da microeconômica heterodoxa, sendo que, por dispersão, se quer dizer que há na literatura pós-keynesiana pesquisas sobre elementos atinentes à teoria da firma. Todavia, não houve preocupação em sintentizar os referidos elementos em um esboço que sumariasse o que é a firma pós-keynesiana. Um caminho para se notar isso é recorrer à obra mais atual sobre os fundamentos da teoria pós-keynesiana, qual seja, Lavoie (2014), que traz uma ampla revisão dos elementos caros ao debate da firma pós-keynesiana, mas que, ao final, continua sem apresentar qualquer agregação em si dos fatores relevantes a que se permita denominar firma (Lavoie, 2014, pp. 123-181).

Há exceções a esta dispersão, com dois autores que buscaram oferecer uma noção mais fechada de firma, Eichner $(1976,1979,1983)$ e Galbraith (1988). Estes autores contribuem em três frentes: (i) a grande firma do sistema capitalista moderno é a megacorporação, atuante em vários mercados, concêntricos ou conglomerados; (ii) o principal objetivo da firma é uma mescla de crescimento com obtenção de poder, mais do que econômico, político e social, sendo que o crescimento é o caminho necessário para o alcance de poder; por fim, (iii) as firmas, para crescer, marcam preços que não são market clearing, mas que são baseados no custo, sobre o qual uma margem é marcada a bem de se alcançar uma meta de lucro que as permita financiar seus planos de expansão tanto internamente quanto externamente.

Uma discussão mais ampla e moderna, porém, característica da dispersão que se nota na teoria pós-keynesiana da firma, é apresentada em Lavoie (2014). O autor, em parte inspirado pelos citados trabalhos de Eichner e Gailbraith, lista os quatro elementos componentes da teoria da firma, são eles, (i) os objetivos da firma, (ii) o formato das curvas de custo e o excesso de capacidade planejado, (iii) a determinação dos preços, e (iv) a relação entre a determinação de preço mais comumente debatida na teoria pós-keynesiana e as contribuições sraffianas sobre preços de produção. A opção de Lavoie (2014) é, no entanto, apresentar as frentes de discussão de todos estes pontos sem os condensar, afinal, em uma firma póskeynesiana. Além disso, o autor extravasa o que se poderia considerar póskeynesiano stricto sensu, com diversas referências que não se filiam a esta escola, como Hall and Hitch (1939), Sylos Labini (1971) e Penrose (2006), mas que servem 
como fonte à teoria da firma pós-keynesiana - sem que, contudo, seus próprios modelos de firma sejam apresentados.

Ao mesmo tempo, algo que chama a atenção em Lavoie é que no compêndio sobre a teoria da firma (2014, pp. 123-181), nenhuma citação a Keynes é feita, de forma que se parece sugerir que o autor nada teria a acrescentar nesta discussão. Como se verá, não se entende neste artigo ser este o caso, inclusive porque na Teoria Geral do Emprego, do Juro e da Moeda, Keynes (1964) destaca que a dinâmica econômica é determinada pelo investimento empresarial que, por sua vez, necessariamente materializa-se em uma firma. Desta forma, a firma é algo caro à perspectiva de Keynes, como o longo esforço de resgate teórico de Lavoie (2014) deixa claro.

Os aspectos gerais que Lavoie (2014) aponta serem característicos das firmas pós-keynesiana envolvem elas atuarem em mercados de competição imperfeita, em que as grandes empresas megacorps possuem e buscam mais poder de mercado. A competição das empresas, aponta o autor, não é via preço, mas centra-se em custos, acesso a recursos financeiros e gastos discricionários de propaganda, pesquisa de mercado, pesquisa e desenvolvimento, gastos em melhoria de produtividade, criação de novos produtos, entre outros. A precificação, por sua vez, é em geral baseada em custos. Estes, por sua vez, têm suas curvas de custos variável e fixo decrescentes inicialmente e constantes após alcançado um determinado nível de capacidade instalada ocupada implicando um custo unitário total em formato L.

Outros dois aspectos trazidos pelo autor são as fronteiras financeira e de expansão que das firmas. A primeira diz respeito à taxa de lucro requerida para um crescimento sustentável da firma, em que ela consiga financiamento externo balanceado com autofinanciamento para custear sua expansão. Por sua vez, neste processo de expansão, a firma precisa buscar eficiência, administrando a compatibilidade de seu tamanho atual com seu crescimento, de suas atividades descentralizadas e em diversificação com a gerência de seus custos, com a ocupação de sua capacidade instalada com a expansão dela, mantendo-se um espaço de produção planejadamente ocioso, para atender variações de demanda ou, como apontava Sylos Labini (1971) enfrentar potenciais entrantes sem pressionar os custos. A preocupação com os custos decorre, por sua vez, de ele ser tanto um dos mecanismos centrais de concorrência, quanto de ele ser a base para a precificação.

Porém, como tantos elementos relevantes, determinação de preços, estrutura de custos, objetivos de médio e longo prazo, sintetizam organicamente uma firma? O esforço do estado das artes pós-keynesiano feito por Lavoie (2014) não oferece esta resposta, pelo menos não sintética e organicamente definindo a 
firma, mesmo tendo-se em sua obra os fundamentos da fronteira do pensamento pós-keynesiano. Assim sendo, o objetivo deste artigo é construir um modelo teórico da firma pós-keynesiana. A contribuição que se oferece é a oferta de um modelo que sintetize a firma pós-keynesiana, que traga consigo uma noção sumarizada dela, agregando nela os elementos caros à literatura microeconômica pós-keynesiana. Ademais, também se destacará o que dentre os escritos do próprio Keynes poderia se oferecer a este debate - por sinal, a basear-se na ausência de referência a ele em Lavoie (2014), o resgate do que Keynes pode contribuir à teoria da firma pós-keynesiana é uma contribuição subsidiária deste artigo à literatura relevante. Ressalta-se, porém, que este artigo, longe de querer esgotar o debate sobre a firma keynesiana, pretende o resumir sem ser apenas uma revisão da literatura, mas oferecendo algo resultante: uma noção de firma na perspectiva póskeynesiana.

$\mathrm{Na}$ estratégia de composição deste artigo, uma questão prática surge: como estruturar um modelo de firma em uma teoria que não modelou sinteticamente sua firma? Pois bem, para enfrentar esta limitação, a estratégia a ser seguida será utilizar-se da perspectiva Visão Baseada em Recursos (de agora em diante RBV, do inglês Resource Based View) como o espelho de uma firma já formada para orientar a procura dos elementos teóricos da firma na escola pós-keynesiana. Mas, por que a RBV?

A escolha se justifica por entender-se que a RBV considera a firma uma instituição cujos recursos, de diversas naturezas, se relacionam de forma bastante orgânica para conformar o que é uma firma em específico. Neste sentido, a RBV releva o papel do empresário, da incerteza, a maneira como os consumidores, a própria firma e os concorrentes interagem dinamicamente (temas caros à obra de Keynes), além de salientar a estrutura da firma de uma forma bastante orgânica, algo que se pretende realizar no modelo de firma que se propõe neste artigo. Logo, seguindo-se Eichner, pode se assumir neste trabalho a RBV enquanto oferecendo "as hipóteses comportamentais necessárias para um modelo microeconômico mais completo" (1985, p. 16). Neste sentido, a RBV, tal qual o que se deseja nesta contribuição, já realizou o esforço de sintetizar os vários elementos relevantes para se especificar uma firma - os chamados recursos na RBV - e, diga-se de passagem, de uma forma muito além de uma mera função de produção, como a firma neoclássica. Portanto, consegue-se ter uma interface que pode ser benéfica para a coleta e o desenvolvimento dos elementos teóricos para se modelar uma firma póskeynesiana. Outro fator claramente importante salientar de partida é que não há 
qualquer elemento na RBV que seja incongruente com a perspectiva póskeynesiana.

Ainda no campo das especificações necessárias ao desenvolvimento do artigo, importa ressaltar que há duas perspectivas na RBV, a que destaca o desempenho da firma e a que se atina ao comportamento dela (Kretzer e Menezes, 2006). A segunda das perspectivas, cujo desenvolvimento seminal é atribuído a Penrose (2006), relaciona-se mais ao objetivo deste artigo, por duas questões, ambas de natureza de afinidade teórica entre a RBV e os pós-keynesianos. Por um lado, há um destaque especial ao papel do empresário no corpo orgânico que forma a firma para esta linha 'comportamental' da RBV. Para Keynes (1964), o empresário é a peça central na dinâmica econômica, pois ele é o tomador da decisão de investimento sendo, assim, responsável pela dinâmica de geração de emprego e renda. Este papel relevante do empresário aproxima elementos caros a ambas as teorias, a partir dos quais a firma pós-keynesiana pode ser estruturada. Por outro lado, Penrose (2006) elenca como fundamentais outros aspectos que também são caros à perspectiva pós-keynesiana, como incerteza, desequilíbrio e interação dinâmica, tanto entre o curto e o longo prazos, quanto entre o ambiente da firma e seu interior. Estes fatores estão todos presentes em Keynes (1964) e constituem peça-chave para a explicação do comportamento empresarial, muito embora Keynes observe o próprio empresário e não a firma, meio pelo qual as decisões empresariais se concretizam. Esta consonância entre elementos relevantes concernentes ao comportamento da firma e termos fundamentais à teoria póskeynesiana explica a opção pela corrente do RBV preocupada com o comportamento da firma, avançada por Penrose (2006).

A estrutura do artigo será dividida em 3 seções, além desta introdução e da conclusão. A seção 2 reúne os principais elementos da RBV no intuito de chegar a uma concepção a priori de firma, estabelecendo um norte para que sejam identificadas suas características, seus objetivos e os meios pelos quais eles são buscados. Na seção 3, pesquisam-se elementos que sejam capazes de formar um conceito de firma pós-keynesiana. O ponto de partida é a obra de Keynes, passando-se depois para os autores pós-keynesianos. Por fim, a seção 4 compreenderá, então, a junção dos elementos que foram apresentados na seção 3, tendo como espelho a estrutura de firma da seção 2, permitindo delinear a firma pós-keynesiana. 


\section{Em busca de um modelo já construído de firma: a contribuição da $\mathrm{RBV}$}

\subsection{A firma da RBV: os recursos e o papel do empresário}

Para Penrose (2006), desempenhos diferentes entre as firmas decorrem do fato de elas serem heterogêneas e deterem distintos recursos ou combinação deles. Logo, duas firmas de mesmo porte estrutural, com o mesmo produto e com recursos semelhantes podem possuir rentabilidades díspares. Segundo Penrose (2006), os recursos, ou ativos, da firma podem ser de dois tipos, tangíveis ou intangíveis. Os tangíveis são visíveis e mensuráveis no processo produtivo e podem ser de duas naturezas: produtivos e financeiros. Os produtivos são aqueles que possuem durabilidade e cuja eficiência pode ser observada no processo produtivo, por exemplo, a vida útil de uma máquina. Já os recursos financeiros são compostos não só pelo capital da firma, mas também pela capacidade dela de ter acesso ao capital externo - financiamentos, entre outros serviços financeiros. Por sua vez, os ativos intangíveis são aqueles não mensuráveis, ou seja, são recursos qualitativos. Eles podem ser desmembrados em: i) os recursos humanos - que são as capacitações e conhecimento do capital humano empregado; ii) a estrutura organizacional - que abrange não só a forma do processo produtivo, mas também o posicionamento do empresário tomador de decisões; e iii) todas as atividades que envolvam um processo de aprendizagem - como o processo de pesquisa e desenvolvimento $(\mathrm{P} \& \mathrm{D})$ em busca de inovação.

Os ativos, juntos, representam a cesta de recursos de uma firma. A montagem e a manutenção de uma cesta de recursos são as responsáveis pela firma estruturar suas operações a bem de seu objetivo último, qual seja, a rentabilidade. Chandler (1967) afirma que a busca pela rentabilidade, por sua vez, é resultado de uma consciência das oportunidades e necessidades para empregar mais dos recursos existentes ou expandi-los. Em termos dinâmicos, Burlamarqui e Proença (2003) explicam o processo de formação destes recursos da firma, ressaltando que,

um recurso é um atributo da firma que não pode ser alterado no curto prazo [...], mas devem ser sempre percebidos em seu caráter de estoque, em contraponto às atividades da firma, pelas quais ocorre o fluxo de receitas, investimentos e despesas. A diferença entre "estoque" e "fluxo" [...] implica que as decisões sendo tomadas no "fluxo" de atividades estarão construindo os "estoques" de recursos futuros da empresa (2003, p. 87-90, grifos do autor).

Para Penrose (2006), o recurso humano tem papel fundamental na composição da cesta de recursos que forma uma firma. Ele pode ser tanto funcionários qualificados bem como aqueles possuem habilidades particulares ao processo produtivo. Este ativo pode ser específico e, portanto, ele é heterogêneo 
entre as firmas. Neste particular, no quadro dos recursos humanos, o empresário detém capacitações e habilidades específicas que o possibilitam exercer função de liderança, sendo ele o tomador de decisões na firma, o responsável por gerenciá-la e por promover maior eficiência organizacional.

Cabe ao empresário, ao longo da composição da cesta de recursos de uma firma, atentar-se para a possibilidade de geração de um novo ativo pela combinação dos já pertencentes à cesta, viabilizando diversidade de recursos. Assim explica-se a necessidade de geração de novos recursos pela ação perspicaz do empresário: a busca de vantagem competitiva para a firma, que se apresente como uma competência essencial para a rentabilidade dela. As competências essenciais surgem da relação entre os recursos, produtivos, financeiros e humanos. Para ser bem-sucedida, esta combinação precisa fazer com que a firma seja capaz de desenvolver capacidades internas que tornem o seu processo produtivo mais eficiente e com que ela obtenha rentabilidade maior do que seus concorrentes. Assim, "as competências essenciais [...] envolvem os mais diversos níveis de trabalhadores com algum grau de qualificação, cujas funções residem em harmonizar fluxos de tecnologia e, também, de organização do trabalho" (Prahalad e Hamel, 1997, p.240).

Contudo, existem limitações à atuação do empresário e da firma. Elas decorrem de informações distintas que os empresários recebem, da ação empresarial e da incerteza do ambiente - que Penrose (2006) entende ser a dificuldade que os empresários e a firma têm de prever o comportamento das demais firmas e do próprio mercado. Tal dificuldade estará sempre presente, já que o empresário não possui conhecimento completo do mercado. Tais limitações relacionam-se (i) à cesta disponível de recursos, (ii) à valoração desses recursos no mercado de fatores estratégicos, (iii) à presença de ativos específicos, e (iv) às capacitações e perspicácia do empresário na formação de estratégias para obtenção de vantagens competitivas sustentáveis ${ }^{1}$.

No que toca às vantagens competitivas sustentáveis, a RBV assume a renda ricardiana na explicação da busca por elas - isto é, a capacidade de a firma obter rentabilidade anormal ao longo do tempo. Mahoney e Padian (1997) chamam tais rendas de empresariais e apontam que elas dependem de fatores de mercado e de características dos recursos próprios, comercializáveis ou não, decorrentes da

\footnotetext{
${ }^{1}$ Barney (1986) argumenta que valor dos recursos desejados para a estratégia de uma firma é incerto e para que se tenha sua parametrização, surge um mercado de recursos importantes para a formação de uma estratégia, isto é, um mercado de fatores estratégicos.
} 
tomada de risco e da perspicácia empresarial em um ambiente complexo e incerto. Em particular, elementos pertinentes às rendas empresariais, como as barreiras à imitação, a busca de patentes e os spillovers, são relevantes. As barreiras à imitação são, de acordo com Peteraf (1993), capazes de restringir o processo de imitação entre as firmas. A busca por patentes, assim como de segredos, são determinantes da sustentabilidade de uma vantagem competitiva. Os spillovers, ou transbordamento de conhecimentos, de acordo com Cohen e Levinthal (1989), são elementos do processo de inovação que aparecem no surgimento de uma nova tecnologia ou serviço.

Para ser sustentável, a vantagem competitiva precisar envolver um conjunto de aspectos: a durabilidade, a não-replicabilidade (ou não-imitabilidade), a nãotransparência e a não-transferibilidade (Grant, 1991). Chandler (1967), por sua vez, destaca a coordenação interna e Barney (1986) ainda cita a não-substitutabilidade de recursos. Especificamente, a durabilidade é a capacidade de um recurso colocar a firma em posição vantajosa em determinado período de tempo sem que seja copiada. A não-replicabilidade associa-se "à capacidade que a firma possui em tornar o menos rápido possível a capacidade de imitação por parte de seu rival" (Grant, 1991, p.125). Neste ponto, a não-transparência correlaciona-se, pois diz respeito à capacidade da firma impedir que outras firmas acessem os elementos centrais de sua estratégia. Ainda que a firma fosse capaz de realizar uma imitação, poderia prevalecer da não-transferibilidade de recursos, isto é, mesmo que eles possam ser comercializados, existem barreiras que impedem algumas firmas de obtê-los, como a imobilidade geográfica, a informação imperfeita, os recursos específicos à firma e a imobilidade de capacitações. A coordenação interna é a capacidade de a firma, por meio do empresário, conciliar seus aspectos organizacionais, produtivos e financeiros, objetivando a maior eficiência produtiva. Por fim, a não-substitutibilidade dos recursos é a dificuldade com que eles podem ser substituídos com recursos de características e finalidades semelhantes. ${ }^{2}$ Salientese que Durand (1999) argumenta que quanto mais eficiente for a coordenação interna da firma, melhor o uso dos seus recursos, e menor a imitabilidade e a transferibilidade deles, tornando mais sustentável a vantagem competitiva. Outro caminho para construção de vantagens competitivas sustentáveis bastante desenvolvido por Penrose (2006) é a diversificação, analisada a seguir.

\footnotetext{
2 Peteraf (1993) considera esse elemento uma limitação ex post à competição, que ocorre quando a firma estabelece recursos dificilmente substituíveis.
} 


\subsection{Diversificação: uma estratégia na busca por vantagem competitiva sustentável}

A diversificação é, inicialmente, resultado da percepção do empresário dos riscos de perda de rentabilidade no mercado em que se encontra. Ela é uma possível maneira de resolução das imperfeições inerentes à atuação da firma, pois quando ela diversifica suas atividades produtivas, segundo Penrose (2006), ela inicia uma produção nova, com o objetivo de alterar ou ampliar seu processo produtivo, serviços e/ou distribuição correntes. Esse processo pode ocorrer sem necessariamente alterar a atual linha de produção, usando o aparato tecnológico disponível, sem maiores custos adicionais; claro, ele também pode acontecer alterando a operação da firma para uma área diferente do que ela realiza, o que pode exigir maiores gastos e esforços relacionados à capacitações e habilidades internas.

No caso em que a firma opta por sair da sua linha de produção, Penrose (2006) lembra que determinados fatores, como as pesquisas industriais e a base tecnológica da firma, são importantes para a diversificação. As pesquisas industriais têm o intuito de não só acompanhar, mas também de prever possíveis mudanças tecnológicas de produtos, processos e técnicas de comercialização. Assim, elas partem da percepção e da busca do empresário por novos mercados lucrativos. Neste sentido, a antecipação de novos produtos em relação aos concorrentes, por exemplo, é capaz de dar vantagens competitivas por patentes, barreiras à imitação ou, simplesmente pelo pioneirismo, à firma que a faz. Não é por menos que a competência com base no desenvolvimento de tecnologias, em complemento ao posicionamento de mercado, "é a condição mais forte e mais duradoura que uma firma pode desenvolver" (Penrose, 2006, p. 189).

Para além, segundo Penrose, "as oportunidades para gerar novos produtos [ou seja, de diversificar] decorrem de mudanças nos serviços produtivos e nos conhecimentos disponíveis na firma [...] bem como de mudanças nas condições externas de oferta e de mercado que são percebidas pela firma" (1959 [2006], p. 179). A geração de oportunidades tem papel crucial quando os processos produtivos das firmas são bastante especializados, bem como no caso em que elas possuem produtos com alta imitabilidade tanto quanto enfrentam dificuldade na renovação tecnológica e no ganho de vantagens por novas tecnologias. Além disso, é preciso que as oportunidades estejam ligadas ao poder de mercado da firma e que elas tenham alguma relação com as práticas mais eficientes e com as capacitações internas dela, pois só assim ela será capaz de trilhar novas áreas por meio da diversificação. 
Contudo, o processo de diversificação tem suas próprias limitações, ditadas pela composição dos recursos da firma, tais como a percepção e atuação do empresário, a presença de ativos específicos e, inclusive, o excesso de recursos gerados pelo processo de diversificação. Com relação ao empresário, Penrose (2006) aponta que a busca pela oportunidade parte da decisão dele e da sua capacidade de fazer uma escolha que seja mais condizente com a estrutura física, organizacional, administrativa e financeira da firma. Suas decisões devem ser tomadas de acordo com as capacitações internas da firma, que a possibilitarão maior capacidade de absorção de informações do mercado. O mesmo vale para a especificidade dos ativos, que pode ser positiva, proporcionando uma vantagem competitiva, ou negativa, ao limitar o processo produtivo pelo alto custo de oportunidade envolvido. Não obstante, Wernerfelt e Montgomery (1988) argumentam que o processo de diversificação pode levar ao surgimento de um excesso de recursos. Isso, por um lado, pode fazer com que a firma tire benefícios de atuar em mercados próximos aos quais opera ou para os quais se diversificou, quando há neles menores barreiras à entrada. Por outro lado, isso também pode resultar em rentabilidades menores, pois a longa duração do processo faz com que uma quantidade maior de concorrentes absorva informações que vão sendo disponibilizadas, de forma que a firma geradora do spillover perca vantagem competitiva ao longo do tempo.

No entanto, Penrose (2006) sugere que além de condições internas à firma, outras condições externas a ela são consideradas estratégicas na diversificação. Além disso, a presença de incerteza e de riscos também é restritiva à estratégia de diversificar para se buscar maior rentabilidade. Tal incerteza está relacionada às expectativas do empresário, enquanto que os riscos são os resultados possíveis de uma dada escolha. Isso faz com que, "os riscos e a incerteza representam o limite fundamental à expansão" (Penrose, 2006, p. 107). A autora lembra também que a obtenção de um número maior de informações é uma das maneiras de reduzir a incerteza objetiva. Então, para que a diversificação represente uma estratégia fundamental para garantir uma coordenação interna mais eficiente e supere as limitações inerentes à firma, ela deverá ser uma combinação favorável entre as oportunidades de mercado e a percepção do empresário.

A Figura 1 sumariza a firma para a RBV. Ela é um conjunto de recursos heterogêneos (cesta) de naturezas tangível (que são mensuráveis) e intangível (não mensuráveis), dividindo-se em cinco categorias, i) produtivos, ii) financeiros, iii) humanos, iv) organizacionais e v) os que passam por algum processo de aprendizagem. A junção entre as duas naturezas de recursos, algo que depende das habilidades e competências do empresário, forma a competência essencial da firma. 
Envolvida por um ambiente de incerteza, tais competências norteiam a firma na escolha de suas estratégias mais eficientes em busca da criação de vantagens competitivas sustentáveis - para tanto, a diversificação é uma estratégia relevante para superar as limitações da firma. Ademais, qualquer alteração nas percepções do empresário, nas capacidades e habilidades e na disponibilidade de recursos, terá como resultado diferentes competências essenciais e novas estratégias de rentabilidade em busca de vantagens competitivas sustentáveis.

Figura 1. A firma para a RBV

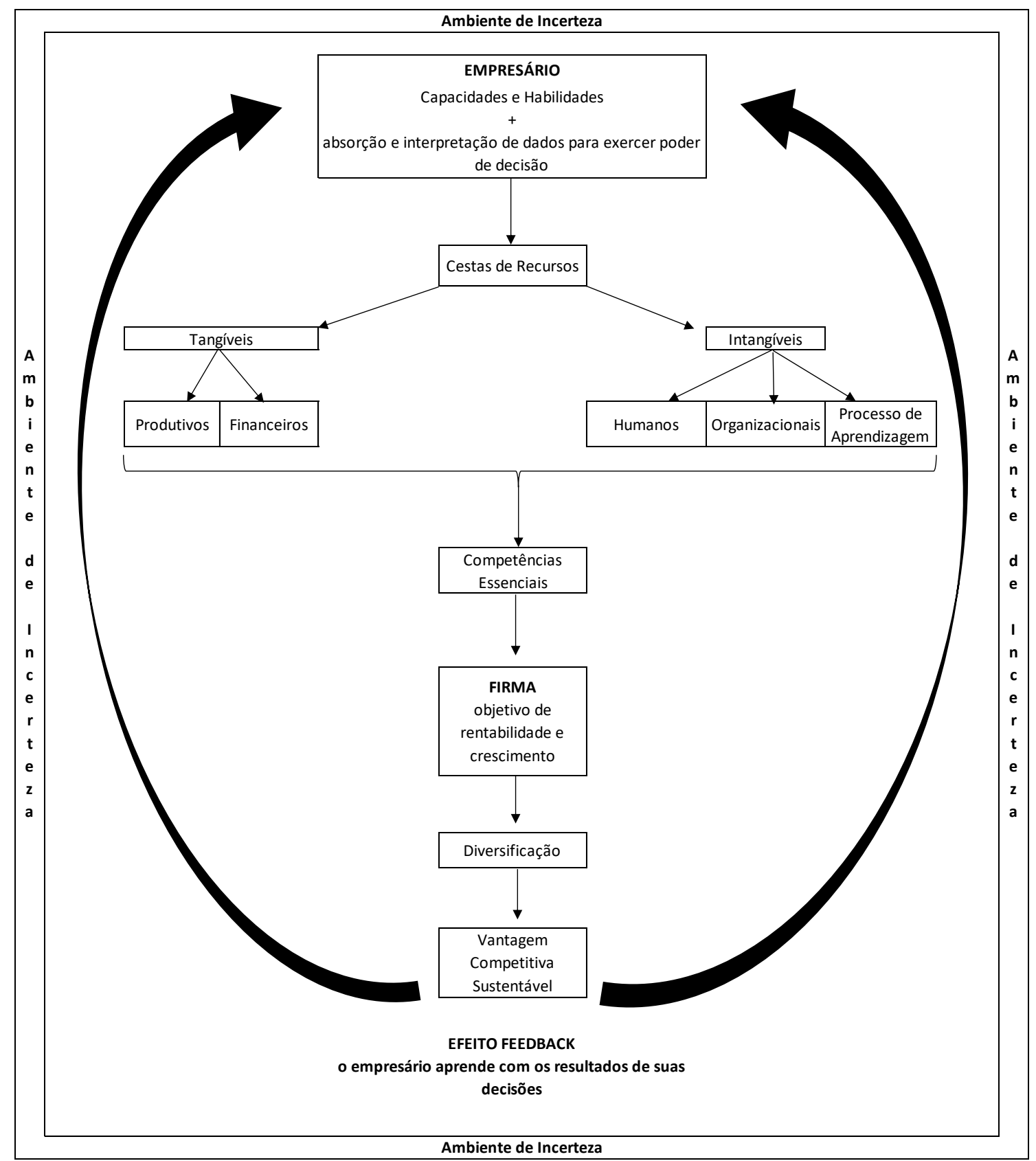

Fonte: Elaboração própria. 


\section{A Firma Pós-Keynesiana: a reunião pelos elementos relevantes}

\subsection{A incerteza, a expectativa, e o papel do empresário nas economias monetárias}

Uma firma pós-keynesiana precisa ser descrita no contexto em que Keynes define o sistema capitalista, as economias monetárias de produção. Nela, os fatores de produção são contratados pelos empresários e o "o processo de produção não poderá iniciar, a menos que a receita de moeda prevista de uma venda seja pelo menos igual aos custos monetários que poderiam ser evitados por não se começar o processo produtivo" (Keynes, 1979, p. 78). Nessas economias, o empresário usa a sua riqueza monetária para obter fatores de produção e insumos que, levados ao processo produtivo, visam permitir que mais moeda seja acumulada com a venda da produção. Então, a economia monetária da produção "é uma economia em que a moeda desempenha um papel próprio que afeta motivos e decisões [...] de modo que o curso dos acontecimentos não pode ser previsto, a longo prazo ou a curto, sem o conhecimento do comportamento da moeda entre o primeiro estado e o último" (Keynes, 1964, p. 408-9).

Porém, confrontado por um futuro incerto e incalculável, outro elemento essencial das economias monetárias, o empresário pode preferir a liquidez da moeda à incerteza de lucro e ao fazer a escolha pela retenção de moeda, gera-se a instabilidade, a criação de desemprego e a estagnação no crescimento do produto, da renda e da riqueza. A incerteza em Keynes é fundamental, isto é, "ao menos alguma informação sobre eventos futuros não pode ser conhecida no momento da decisão, porque essa informação não existe e não pode ser retirada de qualquer banco de dados existente" (Dequech, 1999, p. 415-16).

Nesse particular, a incerteza fundamental tem duas naturezas: a epistemológica, que se relaciona ao processo de conhecimento do indivíduo, e a ontológica, pertinente ao ambiente. No primeiro âmbito, conhecer-se algo resulta de uma combinação de conhecimentos diretos obtidos por meio de informações disponíveis e compreendidas pelo indivíduo, e conhecimentos indiretos, raciocinados a partir do conhecimento direto. Nestas condições, argumenta Dequech (2004), até mesmo o indivíduo com uma grande quantidade de informações não é capaz de saber com certeza todas as informações relevantes à tomada de decisão. Já o caráter ontológico da incerteza decorre de o ambiente estar em constante mutação, pois sempre que algum indivíduo age, altera-se o curto e o longo prazos de uma forma imprevisível - a interação dinâmica que Penrose (2006) trouxe ao RBV. Davidson (1996) entende a incerteza ontológica como oriunda do caráter não-ergódico da realidade. Assim, os eventos não podem ser conhecidos 
por procedimentos estatísticos, o que faz com que o indivíduo não consiga obter, a priori, todas as informações sobre o futuro. Desta forma, "os tomadores de decisão reconhecem que a realidade externa na qual eles operam [é] [...] não só incerta, mas também transmutável ou criativa. [...] no sentido de que o futuro pode ser permanentemente alterado em natureza e substância por ações individuais de grupo e/ou governamentais" (Davidson, 1996, p. 482, grifos do autor).

A relação entre a incerteza do indivíduo e ambiental salienta a relevância da expectativa do empresário para a tomada de decisão, pois ela é a resposta dele à incerteza fundamental vis-à-vis à necessidade de ele tomar decisão para aumentar a acumulação de capital. Nesse particular, as expectativas podem ser de curto e de longo prazos. As primeiras determinam o volume de produto a ser ofertado e seu respectivo preço, enquanto que as expectativas de longo prazo relacionam-se imediatamente com o investimento, isto é, com a aquisição de ativos de capital que o empresário espera the ofereça uma série de retornos futuros suficientes para lhe garantir lucro. Por isso, segundo Keynes (1964), quando há uma piora nas expectativas verifica-se o ciclo redutor do emprego, da renda e da riqueza.

Aliás, Keynes (1964) destaca que as expectativas dependem não só do prognóstico com que são feitas, mas também do estado de confiança do empresário naquilo que ele concluiu. Se ele crê em suas expectativas, ele opta pelo investimento em detrimento da retenção de moeda, exercendo seu animal spirit, pois confronta o desconhecido para efetivar sua vontade de acumular. Ao assim agir, o empresário compra bens de capital que dão vazão a processos produtivos empregadores de recursos antes ociosos. Neste processo, ele cria estoque de capital, conferindo maior riqueza à sociedade.

\subsection{A caminho da firma pós-keynesiana: a constituição e o objetivo da firma}

É pela decisão de investir em ativos produtivos que o empresário constitui a firma. Esses ativos possuem a característica de serem "de longa duração, [permitindo] que sobrevivam por muitos períodos de produção" (Feijó, 1993b, p. 91). Logo, a firma pós-keynesiana é o local por excelência do processo produtivo e é resultante das decisões de investimento do empresário. Ela é, então, a materialização do objetivo dele, qual seja, a busca de subsequentes lucros. Consoante Keynes (1964), a decisão de investimento é um processo que, por um lado, leva em consideração tanto evidências mais ou menos conhecidas pelo empresário, quanto expectativas sobre o futuro. Por outro lado, a constituição da firma também dependerá da confiança que o empresário depositar nas expectativas que formulou. Ainda de acordo com o autor, o empresário em uma economia monetária deve ponderar o custo de oportunidade que a taxa de juros representa 
ao seu investimento produtivo, a depender da relação incerteza versus rentabilidade que o estado de confiança dele apontar em suas expectativas.

Entretanto, de que forma as expectativas são expressas no processo de tomada de decisão, ou seja, como é possível percebê-las? A eficiência marginal do capital exerce essa função, como um dos determinantes fundamentais do investimento. Quando um investimento é realizado, o empresário passa a ter a possibilidade de obter rendas futuras por meio da venda de seus produtos, enquanto seu investimento tiver vida útil. Os empresários detêm, ao realizarem seus planos de investimento, uma expectativa do preço de demanda - retorno total líquido - da venda do que produzirão; estas receitas esperadas serão confrontadas com o preço de oferta do ativo de capital - custo do investimento - que viabilizará a referida produção. Essa relação entre a renda esperada do investimento e o preço de oferta do ativo de capital é a eficiência marginal do capital. Sendo a eficiência marginal do capital, em parte, a expressão das expectativas que cercam a decisão do empresário, o investimento será feito apenas se a taxa de retorno esperada pelo menos equivaler os juros oferecidos por ativos financeiros.

As expectativas de retorno no longo prazo, ou seja, durante a vida útil do bem de capital adquirido pelo investidor são, segundo Feijó "fundamentalmente independentes, em sua formação, de expectativas de curto prazo" (1993b, p. 92). Elas não podem ser conferidas por meio de resultados obtidos no curto prazo e, assim, os empresários sustentam suas decisões de efetivar o investimento exclusivamente baseados em seu estado de confiança nas expectativas de longo prazo. O que os resultados de curto prazo oferecem às expectativas de longo prazo de um empresário são dados que ele usa para formar sua opinião e seu estado de confiança sobre o que um novo investimento futuro poderá lhe trazer. As expectativas de curto prazo, por sua vez, podem ser entendidas como os ajustes nos preços e na produção durante a vida útil de um bem de capital. Logo, esta expectativa é posterior à decisão de longo prazo e ela pode ser, e via de regra o é, refeita várias vezes ao longo da duração de um ativo de capital. Neste sentido, se os resultados de curto prazo indicam que a demanda efetiva está sendo equivalente à oferta produzida, novas expectativas positivas de longo prazo podem ser formadas, levando os empresários a realizarem investimentos ex post.

Neste particular, é possível distinguir em Keynes (1964) dois tipos de investimento, o ex ante e o ex post. $O$ primeiro é o investimento que antecede o processo produtivo, ou seja, é aquele planejado para que a produção se inicie. Já investimento ex post dará continuidade à produção, possibilitando à firma permanecer em seu processo de crescimento e acumulação. Para Eichner (1985) e 
Lavoie (2014), a decisão de investimento ex post envolve a firma ser capaz de gerar financiamento interno e/ou externo. O funding interno geralmente é obtido por meio da precificação da empresa, que deve prever uma margem de lucro sobre os custos unitários de produção. Estes custos são em geral levam em conta os custos diretos de produção e os fixos, relacionados à gerência da produção e à administração da empresa. O nível de produção, por sua vez, é estabelecido a partir do planejamento para subutilização da capacidade produtiva (Harcourt e Kenyon, 1992).

A margem de lucro é determinada a partir da "demanda (curva da eficiência marginal do capital) e da oferta de fundos adicionais de investimento por parte da firma ou grupo de firmas que têm, dentro da indústria, o poder de estabelecer o preço - poder este exercido, na maioria dos casos, pelo líder de preços na indústria" (Eichner, 1985, p. 10). Dado seu poder de mercado, a firma marca sua margem de retorno requerida e, assim, define seus preços para obter um fluxo de recursos que a permita investir mais, buscando rentabilidade crescente para enfrentar as limitações financeiras e técnicas ao seu contínuo crescimento. A realização da margem estabelecida oferta à empresa lucro que, retido, configura a principal fonte de recurso para a firma se expandir (Lavoie, 2014). A expansão da empresa, resultante de todo este processo, é o meio de ela obter continuamente mais condições de enfrentar suas limitações, como a concorrência, a incerteza, e as restrições ao financiamento externo ${ }^{3}$. Assim, enquanto o objetivo do empresário é o lucro contínuo, para que isso se sustente a longo prazo, parte do lucro realizado é reinvestido na firma, expandindo-a.

\subsection{Tipos de mercado, competitividade, decisões de preço e produção e limitações da firma}

Para Eichner (1985) existem dois tipos de mercado a serem considerados: o competitivo e o oligopólio. O competitivo é uma estrutura em que há um número grande de firmas, com produtos semelhantes e, por isso, substitutos entre si, além de ser um mercado de mais fácil entrada em relação ao oligopólio. Isso sugere uma maior volatilidade, com preços e produção sofrendo alterações no curto prazo, à medida que o comportamento da demanda se altera em relação ao que é esperado pelos empresários. Por fim, seu poder de decisão sobre os preços e produção é reduzido, ainda que exista.

\footnotetext{
${ }^{3}$ As fontes de financiamento externo podem ser os empréstimos bancários e outras formas de dívida, como debêntures e dívidas privadas, como sugere Eichner (1985), ou o lançamento de ações, como destaca Feijó (1993b).
} 
No oligopólio, segundo Lavoie (2014) estrutura de mercado vastamente majoritária nas economias monetárias, tanto o preço quanto a produção e os custos são variáveis caracterizadas por constância ao longo do tempo e sobre ambos a firma tem elevado poder de decisão. Em linha, Feijó (1993b) aponta que a tendência nesse mercado é a firma, em particular a líder, se encontrar em uma fase avançada ou madura, no qual firmas marginais já foram eliminadas ou simplesmente exercem o papel de seguidoras. Porém, nesse cenário a competição entre as poucas grandes firmas é maior, na luta por uma maior parcela do mercado.

No tocante especificamente ao comportamento da firma, para que ela consiga sobreviver ao longo do tempo, é fundamental que sua organicidade consiga produzir uma característica importante da firma pós-keynesiana, a competitividade. Quando a firma adquire competitividade, ela tem maior capacidade de ditar a margem sobre seus custos e tem maior market-share, elementos fundamentais para que ela consiga ultrapassar as barreiras financeiras e técnicas a sua expansão de longo prazo. Se sua estratégia gerência é hábil o suficiente para viabilizar competitividade ao longo de todas as expansões que a firma fizer, ela incorre em melhores chances para ampliar sua competitividade, entrando em um círculo virtuoso competitividade-lucros-expansão.

Neste sentido, Feijó (1993b) argumenta que na decisão de preços, a realização do objetivo da firma dependerá da forma pela qual ela consegue manipulá-los a bem de estabelecer o mark-up sobre os custos de produção. Neste contexto, Eichner aponta que as firmas que não possuem essa prática cobram "os preços estabelecidos pelas empresas [...] líderes” (1985, p. 4). Todavia, há limites no poder de marcação de preços, principalmente em oligopólios com maior competição, pois preços maiores podem gerar o efeito contrário ao desejado - a diminuição do fluxo da receita por conta da sensibilidade preço da demanda, cuja razão em geral, aponta Lavoie (2014), decorre da relação de fidelização que as empresas buscam construir com seus clientes, o que é, por sinal, um dos fatores que explicam a constância de preços que se mencionou acima. Vale ressaltar, como o faz Feijó (1993b), que a decisão de preço, ainda que de curto prazo, traz consigo uma importante questão de longo prazo, pois "incorpora uma decisão sobre a taxa a qual a firma irá crescer no longo prazo" (Feijó, 1993b, p. 89). Pode-se perceber, portanto, que existe uma ligação entre as decisões de preço e investimento, já que a primeira é um dos caminhos pelo qual a firma será capaz de obter o financiamento para seus investimentos ex post.

Por sua vez, a decisão de produção é a quantidade que a firma escolhe ofertar e, como Keynes (1964) denota, baseia-se nas expectativas de curto prazo do 
empresário, tanto as relacionadas aos custos, quanto ao resultado já obtido das vendas da produção. Ela é, então, pautada pelas expectativas sobre o comportamento do mercado e são elas que determinam o volume de emprego efetivamente ofertado pelas empresas. Keynes (1964) aponta que essa decisão, via de regra, baseia-se em um raciocínio convencional de que os resultados futuros serão repetições das vendas correntes. Ver-se-á tal situação, em especial em mercados maduros e consolidados, nos quais existem maior estabilidade e constância dos resultados obtidos, sugerindo uma previsão menos incerta da trajetória do mercado, como observou Eichner (1985). Empresas que já possuem maior poder de mercado, que detiveram processo de crescimento e ganharam competitividade, conseguem administrar melhor eventuais variações de demanda, usando, para tanto, administração de sua capacidade produtiva, sobretudo no espaço em que as curvas de custo são horizontais.

Nesse particular, uma característica que Feijó (1993b) traz à discussão sobre a decisão de produção é que ela depende da percepção que os empresários têm sobre os preços futuros, afinal, é isso que o eles esperam receber pelo esforço produtivo, lembrando que o preço é corrente e não determina o que será o preço de amanhã diante de decisões de produção ou investimento presentes. Entretanto, ainda sim, ela é capaz de influenciar estas referidas decisões, principalmente o investimento ex post, já que o preço é determinado objetivando obter margem de lucro suficiente para gerar financiamento interno e gerar colateral suficiente para enfrentar eventuais restrições de crédito. Assim sendo, Feijó (1993b) afirma que a decisão de produção também é estabelecida pela relação entre os preços corrente e futuro. Note-se que a decisão de produção envolve o princípio da temporalidade das economias monetárias da produção. Mesmo que ela seja uma decisão caracteristicamente de curto prazo, suas repercussões se dão ao longo do tempo e não podem ser revertidas. Além disso, essa decisão depende do comportamento dos preços correntes e o que os empresários esperam dos preços futuros. Apesar de Keynes (1964) dar maior importância para a decisão de produção, os póskeynesianos, como Eichner (1985) e Lavoie (2014), dão maior foco à decisão de preços, principalmente por ser ela uma das determinantes financeiras do investimento ex-post, fator essencial à obtenção de lucros e, paralelamente, ao crescimento de longo prazo da firma.

Assim sendo, existem limites inerentes a cada decisão, que podem dificultar que ela corresponda à expectativa do empresário. Porém, à medida que a firma amadurece, ela é capaz de reduzir esse tipo de limitação, estando sujeita à sua própria capacidade de crescer à longo prazo, aquilo que Lavoie (2014) chama de 
fronteira de expansão. Dessa maneira, Feijó (1993a; 1993b) argumenta que há limites para a competitividade da firma, decorrentes da sua capacidade de manipular seus preços, sugerindo a diversificação como uma possível solução. Ela é capaz de enfrentar a incerteza, ampliando seu leque de investimentos e, além disso, a firma embarca em um novo mercado que a permite não só ter mais espaço para proporcionar maiores margens de lucro via preços e produção, como também, apoiada pelo desenvolvimento de novas tecnologias e um planejamento estruturado. Nesse particular, Santos e Crocco (2000) entendem que a consciência da existência desse limite é o ponto de partida para a importância das mudanças tecnológicas para os pós-keynesianos.

\subsection{Mudanças tecnológicas, cesta de recursos e suas repercussões sobre a firma}

Se a tecnologia é importante, quais as consequências dela no processo produtivo? Galbraith (1988) enumera seis, e, diga-se de passagem, tema negligenciado no citado compêndio de Lavoie (2014). A primeira diz respeito ao lapso de tempo entre a decisão de produzir e o produto final. $\bigcirc$ emprego de tecnologia acompanha a necessidade de evolução do processo produtivo da firma, que passa a ser conduzido com uma maior segmentação das etapas. $\bigcirc$ uso contínuo da tecnologia leva à segunda consequência, o aumento do capital investido no processo produtivo. Neste ponto, o investimento em tecnologia pode tanto potencializar a competitividade da firma, caso o empresário consiga ter uma visão mais acurada do que o futuro trará à competição, quanto prejudicá-la, com o emprego de uma máquina que se torne defasada antes do período de uso esperado. Isso sinaliza a terceira consequência, "com o crescimento da tecnologia, o emprego de tempo e dinheiro tende a ser feito de maneira mais inflexível com relação ao desempenho de determinada tarefa" (Galbraith, 1988, p. 23). Em outras palavras, o uso da tecnologia a longo prazo envolve, além da necessidade de maior volume de investimento, conhecimentos diferentes e específicos, fazendo com que a firma se mantenha em linha com uma trajetória tecnológica, realizando mudanças a partir do seu conhecimento em alguma tecnologia desenvolvida previamente.

A quarta consequência alude ao conhecimento específico necessário para que a tecnologia seja utilizada eficientemente. Logo, a especialização da mão de obra é requerida, fazendo com que o processo de inovação seja condicionado pelas capacitações inerentes e adquiridas pela firma. A quinta consequência é a necessidade de a firma se organizar, como contrapartida da especialização. É esta organização "que faz com que o trabalho de especialistas chegue a um resultado coerente" (Galbraith, 1988, p. 24). Por fim, a sexta consequência une todas as demais para sugerir que diante de um "aumento do tempo e capital que devem ser 
investidos, na inflexibilidade desse investimento, das necessidades da grande organização e dos problemas da atitude do mercado sob condições de tecnologia avançada, vem a necessidade do planejamento" (Galbraith, 1988, p. 24).

Dessa forma, a implantação de tecnologia no processo produtivo, apesar de seus entraves como a inerente incerteza sobre seu sucesso e/ou a necessidade de um conjunto de capacitações pré-existentes, é essencial para a sustentação da competitividade e do crescimento de uma firma. Isso é especialmente importante quando a manipulação de preços e da produção se tornam insuficiente para manter a obtenção de lucro a longo prazo, caso comum na dinâmica das economias monetárias.

\section{A Firma Pós-Keynesiana: um modelo sintético}

Os pós-keynesianos, por um lado, preocupam-se com a determinação de preços com vistas à obtenção de margens de lucro para o investimento, como é caso de Eichner (1985) e Lavoie (2014). Por outro lado, autores como Gabrailth (1988), abordam as decisões de produção, a estruturação do processo produtivo e as repercussões da tecnologia nas estruturas produtivas. Feijó (1993b) aglomera as três decisões (investimento, preços e produção) aos elementos presentes nas obras de Keynes, como é o caso da incerteza e do papel da moeda. Contudo, o que se percebe é que no caso da teoria pós-keynesiana, o conceito e, sobretudo um modelo da firma são ainda dispersos. Cabe, agora, apresentar os elementos que, sinteticamente, trazem a mente o que seriam as componentes que, organicamente, definem a noção de firma pós-keynesiana. Para isso, ter-se-á em mente a firma da RBV e, assim, pode-se apresentar a firma pós-keynesiana via sete elementos que a definem e que se distribuem nos principais elementos que a constituem - sua composição, características, objetivos e limitações.

i) A firma é um conjunto de recursos (ativos), vários deles específicos a ela. $\mathrm{Na}$ firma pós-keynesiana essa característica não é apresentada como um atributo por nenhum autor, mas é necessária, pois a firma sempre será um arranjo de ativos, financeiros, produtivos e humanos, que comporá o que é a firma a partir da decisão de aquisição de ativos do empresário. Não obstante, é a diferença dos ativos detidos entre uma firma e outra que a confere competitividade no processo concorrencial em que se encontra e que faz as firmas serem dinâmicas e heterogêneas.

ii) O porte da firma como resultado de seu objetivo de expansão. A firma pós-keynesiana típica é uma grande empresa, diversificada, que é deste porte para enfrentar as vicissitudes de atuar em um oligopólio. $\bigcirc$ porte da firma é resultado 
de seu estado evolutivo, momento em que ela está com grande inserção e poder de mercado, de maneira que o empresário tem a capacidade de ter maior controle sobre suas decisões, fundamental para que seu objetivo, lucro, seja também possível ao longo do tempo.

iii) A busca por rentabilidade. As rentabilidades crescentes são objetivo intermediário de uma firma pós-keynesiana, meio para que seu fim, crescimento contínuo e sobrevivência, ocorra. Esse objetivo justifica-se pela materialização, por meio da firma, da vontade do empresário em obter mais riqueza na forma de moeda, ou seja, lucros monetários crescentes.

iv) Competitividade. A competitividade está associada ao processo decisório e à capacidade do empresário em bem organizar seus recursos e tirar deles a melhor eficiência possível, capaz de enfrentar as limitações técnicas do processo de expansão, a criação de novos mercados, o enfrentamento da concorrência. É a característica que define a habilidade da empresa em se movimentar, na busca por seu maior porte, financiado pela rentabilidade crescente. Competitividade significa maior chance de obtenção de poder de mercado, de forma que a competitividade define a captura de parcelas crescentes da demanda.

v) O papel essencial do empresário. Todos os fatores acima listados dependem crucialmente do papel do empresário, que é um elemento central antes mesmo que a firma exista, pois ele é o detentor de riqueza e poderá ou não optar pelo investimento em um processo produtivo, que constitui a firma. Além disso, ele possui habilidades e capacidades que o distinguem e o destacam em relação aos demais ativos que compõem uma firma, atribuindo a ele a função de criador e tomador de decisões. Então, não basta apreender a firma a partir do momento em que ela está estruturada, mas, é essencial denotar a motivação para sua criação, isto é, o intento do empresário em lucrar, posto que está em uma economia monetária de produção. Assim, o empresário é o ator formador e mantenedor da firma, é ele quem realiza o investimento inicial e os demais investimentos ex post, é o recurso mais inexorável da firma.

vi) Incerteza fundamental. As expectativas de curto e longo prazos são a forma pela qual o empresário lida com a incerteza fundamental. Suas expectativas de longo prazo prospectam seus investimentos, seja o inicial e os ex-post. Para tanto, o empresário conta com os recursos disponíveis e com os que poderão ser adquiridos e/ou criados em favor do processo produtivo, o que exige que ele esteja presente no gerenciamento do processo produtivo. Ademais, intensifica a incerteza, e o papel do empresário defronte ela, o tempo ser unidirecional. No curto prazo, as decisões podem ser revistas, mas isso implica a firma incorrer em custos. Porém, as 
decisões de longo não podem ser refeitas, elas são cruciais. Assim, a grande preocupação dos empresários neste processo dá-se pela irreversibilidade do tempo e as consequências que uma decisão pode gerar no futuro. Isso é agravado pelo ambiente incerto, que está em constante mutação e muda as informações disponíveis ao empresário a todo tempo. Porém, a todo tempo o empresário está agindo para que a materialização de seu objetivo de lucro se materialize na firma. Enfim, o empresário e, por consequência, a firma, não é capaz de reunir todas as informações necessárias para o conhecimento pleno. Essa situação é agravada por conta de cada movimento de um concorrente em gerar modificações no mercado, que são impossíveis de serem completamente previstas ou absorvidas pelos empresários.

(vii) A tecnologia é estruturante da firma. O desenvolvimento de inovações em produto e processos produtivos indica a preocupação da firma em tomar a tecnologia como parte estruturante de si, deixando de ser um fator exógeno. Além disso, Galbraith (1988) lembra que o empresário deve estar atento a essas mudanças, acompanhando-as por um planejamento, para que o objetivo de obter rentabilidade que financie seu crescimento se realize. Aliás, a característica de a firma seguir uma trajetória tecnologia ressalta o caráter dinâmico e evolutivo dela.

Portanto, como a Figura 2 sintetiza, a firma pós-keynesiana é a vontade do empresário em acumular capital, materializada por meio do investimento ex ante em um processo produtivo que é constituído com ativos produtivos, financeiros e humanos, em uma economia monetária de produção caracteristicamente incerta e dinâmica. Nela, as expectativas de curto e longo prazos sobre o comportamento da demanda efetiva são inter-relacionadas e afetam diretamente o processo decisório. Com a firma com maior competitividade terá maior poder de mercado e será capaz de um maior controle nos preços e na produção, facilitando suas condições internas em superar as restrições financeiras e técnicas para sua expansão ao longo do tempo, meio de os lucros desejados pelo empresário continuarem a ser obtidos. Porém, as condições internas encontram limites internos e externos, como as oscilações da demanda, erro expectacional, a concorrência, os quais podem ser superados pelo uso da tecnologia em favor da diversificação, de processo e de produto, da firma. 
Figura 2. A firma pós-keynesiana

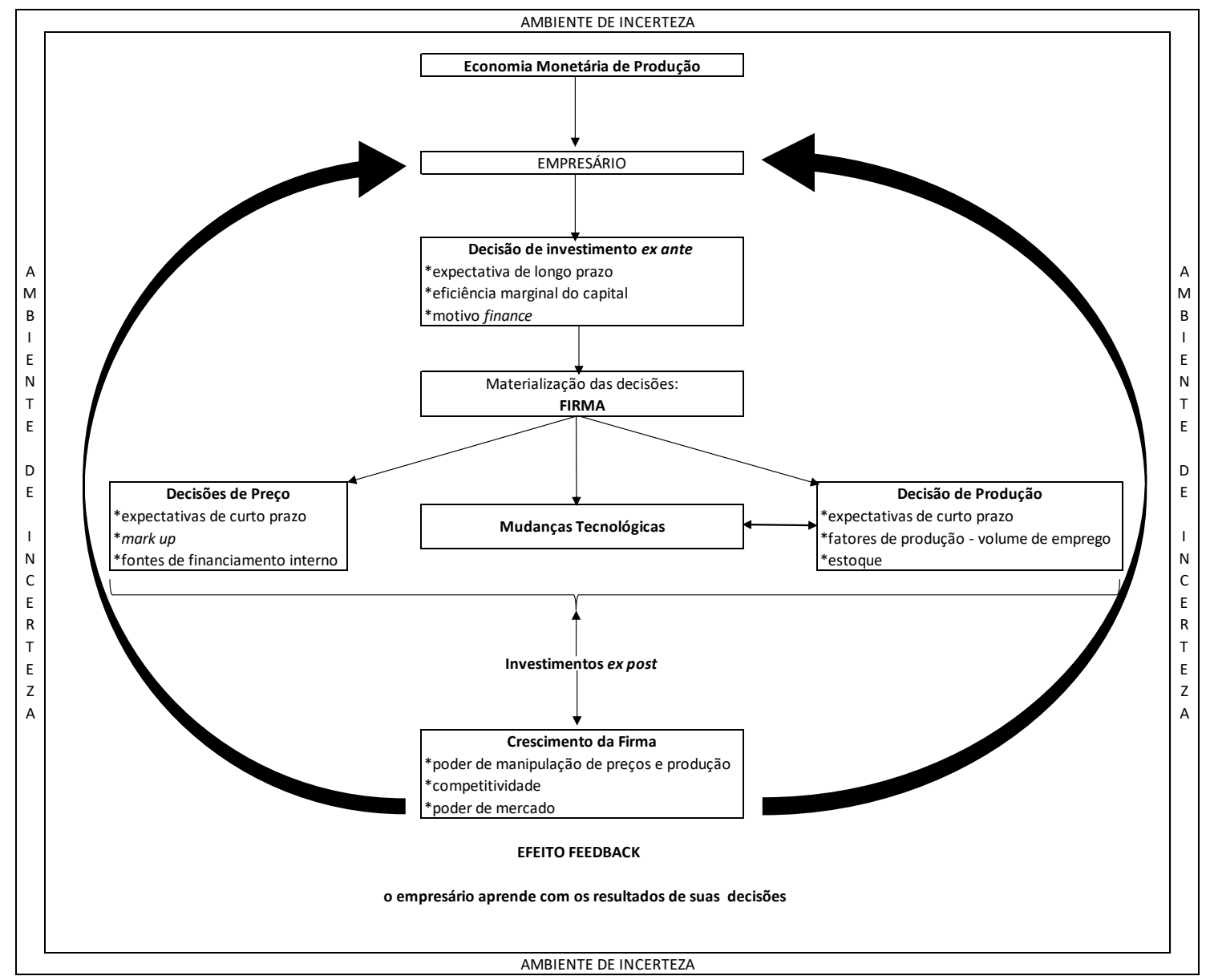

Fonte: Elaboração própria.

\section{Conclusão}

Diante da revisão da literatura realizada e tendo a RBV como um espelho do que vem a ser um modelo de firma já consolidado, a síntese da firma póskeynesiana foi compreendida como um arranjo de ativos produtivos, financeiros e humanos materializados pela vontade do empresário em formar um portfólio que lhe possa conferir lucros e, assim, ampliar sua riqueza. $\bigcirc$ processo produtivo só será iniciado se o empresário tiver expectativa de retorno acima dos custos envolvidos na produção. Logo, o objetivo da firma, materialização da vontade do empresário, é ofertar lucro ao(s) seu(s) detentor(es) ao longo do tempo e, para isso, seu objetivo final é crescer.

O empresário, logo, tem papel central, pois é ele quem usa de seu animal spirite cria a firma, diante de um modelo dinâmico em que as expectativas de curto e longo prazos são inter-relacionadas. Contudo, o empresário é confrontado pela incerteza, de forma inexorável, ao tomar a decisão de investimento ex ante, 
baseado em suas expectativas de longo prazo. Ele inerentemente desconhece o resultado que advirá de sua composição de ativos, embora no curto prazo, por meio das decisões de preço e produção, busque ajustar suas decisões para que os proventos sejam lucrativos.

As decisões de preço e produção dependem da competitividade da firma. As decisões a serem tomadas pelo empresário também dependem diretamente do poder de mercado detido pela firma, o que reforça o elemento competitividade. Há uma relação endógena entre poder de mercado e competitividade: quanto maior um, maior o outro. Dessa forma, para a pós-keynesiana da firma, o que determina reações e resultados distintos em mercados diversos é a competitividade da firma vis-à-vis às demais firmas da indústria. Porém, para a manutenção da competitividade, a firma depende de um elemento que vai além, que é a capacidade de a competitividade superar as barreiras financeira e técnica a sua expansão de longo prazo. Quando a possibilidade de obtenção de lucros e de crescimento é esgotada, a maneira para ampliar a lucratividade da firma é o uso da tecnologia para inserir novos produtos no mercado ou, até mesmo, adentrar em outros - isso é a diversificação da firma. Nesta síntese, têm-se os sete elementos orgânicos da firma, quais sejam, o um conjunto de recursos (ativos), vários deles específicos a ela; o seu porte resultar de seu objetivo de expansão; a busca por rentabilidade é o caminho para seu crescimento; a competitividade é que garante que a busca de rentabilidade se realize; o papel essencial do empresário em fazer com que a firma aconteça e exista; e a tecnologia é estruturante da firma.

Há muito ainda a ser desenvolvido acerca da firma pós-keynesiana e este trabalho pretende ser visto com uma tentativa nesta direção. A reunião de elementos que configuram uma firma e o adensamento deles em um sentido lógico que permitisse perceber o que ela é, a que serve, como se comporta, quais limitações enfrenta e como faz para superá-las sustentavelmente, oferece à perspectiva pós-keynesiana material para próximos passos. É importante para a teoria pós-keynesiana buscar 'microfundamentar-se', afinal, o estudo do agregado, isto é a macroeconomia (que tem Keynes como um de seus fundadores) não decorre de outra coisa que não as decisões microeconômicas, que em muito se materializam na firma. 


\section{Referências}

Barney, J. B. (1986). Strategic Factor Markets: Expectations, Luck, and Business Strategy. Management Science, 32(10), 1231-1241. https://doi.org/10.1287/mnsc.32.10.1231

Burlamaqui, L., \& Proença, A. (2003). Inovação, Recursos e Comprometimento: Em Direção a uma Teoria Estratégica da Firma. Revista Brasileira de Inovação, 2(1), 79-110. https://doi.org/10.20396/rbi.v2i1.8648869

Chandler, A. D. (1967). Strategy and Structure. Cambridge: MIT Press.

Cohen, W., \& Levinthal, D. (1989). Innovation and learning: the two faces of R\&D. Economic Journal, 99(397), 569-596.

Davidson, P. (1996). Reality and Economic Theory. Journal of Post Keynesian Economics, 18(4), 479-508. https://doi.org/10.1080/01603477.1996.11490083

Dequech, D. (1999). Expectations and confidence under conditions of uncertainty. Journal of Post Keynesian Economics, 21(3), 415-430.

Dequech, D. (2004). Uncertainty: Individuals, institutions and technology. Cambridge Journal of Economics, 28(3), 365-378. https://doi.org/10.1093/cje/28.3.365

Durand, R. (1999). The relative contributions of inimitable, non transferable and non substitutable resources to profitability and market performance. In M. Hitt, P. Clifford, R. Nixon, \& K. Coyne (Eds.), Dynamic Strategic Resources (pp. 67-95). Nova York: J. Wiley.

Eichner, A. (1976). The Megacorp and Oligopoly: Micro Foundations of Macro Dynamics. Cambridge University Press: Cambridge.

Eichner, A. (1979). A Guide to Post Keynesian Economics. White Plans: Nova York.

Eichner, A. (1985). Uma Teoria da Determinação do Mark-Up sob Condições de Oligopólio. Ensaios FEE, (2), 3-22.

Eichner, A. S. (1983). The micro foundations of the corporate economy. Managerial and Decision Economics, 4(3), 136-152. https://doi.org/10.1002/mde.4090040304

Feijó, C. A. (1993a). A firma em um Ambiente Inflacionário: uma visão póskeynesiana. Revista Analise Econômica, 11(19), 122-135. 
Feijó, C. A. (1993b). Decisões empresariais numa economia monetária de produção: notas para uma teoria pós-keynesiana da firma. Revista de Economia Política, 13(1), 82-100.

Galbraith, J. K. (1988). O Novo Estado Industrial. São Paulo: Nova Cultural.

Grant, R. M. (1991). The Resource-Based Theory of Competitive Advantage: Implications for Strategy Formulation. California Management Review, 33(3), 114-135. https://doi.org/10.2307/41166664

Hall, R. L., \& Hitch, C. J. (1939). Price Theory and Business Behaviour. Oxford Economic Papers, 2(1), 12-45. https://doi.org/10.1093/oxepap/os-2.1.12

Harcourt, G. C., \& Kenyon, P. (1976). Pricing and the investment decision. Kyklos, 29(3), 449-477. https://doi.org/10.1111/j.1467-6435.1976.tb01984.x

Keynes, J. M. (1964). The General Theory of Employment, Interest and Money. Nova York: HBS.

Keynes, J. M. (1979). The General Theory and After: a supplement. In The Collected Writings of John Maynard Keynes (Vol. XXIX). Londres: Royal Economic Society.

Kretzer, J., \& Menezes, E. A. (2006). A importância da visão baseada em recursos na explicação da vantagem competitiva. Revista de Economia Mackenzie, $4(4), 63-87$.

Lavoie, M. (2014). Post Keynesian Economics: New Foundations. Aldershot: Edward Elgar.

Mahoney, J. T., \& Padian, R. (1997). The Resource-Based View Within the Conversation of Strategic Management. In N. J. Foss (Ed.), Resources firms and strategies: a reader in the Resource-Based Perspective (pp. 363-380). Oxford: Oxford Management Readers.

Penrose, E. (2006). The Theory of the Growth of the Firm. Oxford: Basil Blackwell. Peteraf, M. (1993). The Cornerstones of Competitive Advantage: A Resource-Based View. Strategic Management Journal, 14(3), 179-191.

Prahalad, C. K., \& Hamel, G. (1990). The Core Competence of the Corporation. Harvard Business Review, 68(3), 79-91. https://doi.org/10.1007/3-54030763-X_14

Santos, F., \& Crocco, M. (2000). Technology and the Need for an Alternative View of The Firm in Post Keynesian Theory (No. 148). Texto para Discussão. Texto para discussao, Belo Horizonte: UFMG/Cedeplar. 
Sylos-Labini, P. (1971). La Theorie des prix en regime d'oligopole et la theorie du development. Revue D'Economie Politique, 81(2), 244-272.

Wernerfelt, B., \& Montgomery, C. A. (1988). Tobin's q and the Importance of Focus in Firm Performance. The American Economic Review, 78(1), 246-250. https://doi.org/10.2307/1814713 